\title{
Online educational methods vs. traditional teaching of anatomy during the COVID-19 pandemic
}

\author{
Trifon Totlis ${ }^{1}$, Maksim Tishukov ${ }^{1}$, Maria Piagkou $^{2}$, Michael Kostares $^{2}, K_{\text {Konstantinos Natsis }}^{1}$ \\ ${ }^{1}$ Department of Anatomy and Surgical Anatomy, School of Medicine, Faculty of Health Sciences, Aristotle University of Thessaloniki, Thessaloniki, \\ ${ }^{2}$ Department of Anatomy, School of Medicine, Faculty of Health Sciences, National and Kapodistrian University of Athens, Athens, Greece
}

\begin{abstract}
Aim of the present study was to determine the impact of the COVID-19 outbreak on anatomy teaching to medical and dental students comparing the traditional anatomy teaching with three remote teaching modalities. A cross-sectional study was conducted among undergraduate medical and dental students of the Aristotle University of Thessaloniki. Four hundred and twenty students who attended anatomy classes during COVID-19 outbreak in Greece, were asked to fill in a questionnaire of 22 questions evaluating the formats of the different courses provided. Each student was asked to complete the questionnaire anonymously via the Google Forms ${ }^{\circledR}$ platform. A total of 200 students participated. During the lockdown, $59.5 \%$ of students attended all online anatomy lectures compared to $44.5 \%$ in the pre-pandemic year. Overall, the higher percentage of $73.5 \%$ was satisfied with the traditional anatomy teaching, instead of $56 \%$ which were satisfied with the effectiveness of online anatomy lectures. Asking whether any remote educational method can partially or completely replace the traditional anatomy teaching, the majority of students replied "no" for all the three remote modalities. The traditional anatomy teaching remains the most preferred and effective teaching modality. The students ranked online anatomy lectures and pre-recorded anatomy lectures in second place in terms of effectiveness and preference. The development of remote learning methods has increased students' active participation in anatomy lessons, but significantly negatively affected the students' performance at exams. Remote learning cannot replace the traditional anatomy teaching method, but online lectures could be incorporated into anatomy curricula as an additional tool.
\end{abstract}

Key words: Anatomy, Education, Teaching, COVID-19, Online education

Received January 19, 2021; 1st Revised January 28, 2021; 2nd Revised April 8, 2021; Accepted April 26, 2021

\section{Introduction}

The COVID-19 pandemic has had a huge impact on many aspects of the human life, including all levels of education, and especially medical education. The majority of medi-

\footnotetext{
Corresponding author:

Trifon Totlis (ib

Department of Anatomy and Surgical Anatomy, School of Medicine, Faculty of Health Sciences, Aristotle University of Thessaloniki, Thessaloniki 54124, Greece

E-mail: totlis@auth.gr
}

cal schools around the world have shifted towards remote learning. Almost 10 months after the COVID-19 pandemic emerged, virtual learning seems to be the only sustainable option in medical education and especially in anatomy education $[1,2]$. While any theoretical lecture could be effectively delivered in online classrooms, learning anatomy exclusively in this mode is challenging, because teaching anatomy requires three-dimensional (3D) perception and depends on the student's engagement with the online resources [3].

Human anatomy is one of the most important and classic parts of the curriculum of medical schools around the world. Deep knowledge of anatomy is essential for all physicians, 
regardless of their specialty. The shift of Greek Universities to remote education due to COVID-19 restrictive measures has limited the opportunities for full-time education of medical students, which inevitably led to the use of remote teaching methods. Anatomists have been playing a pivotal role in driving the innovation of digital education for several years and host to e-learning programs [4]. The resources have been used to complement traditional teaching methods in anatomy [5] and have been shown to improve student learning outcomes [6]. In the period after the introduction of COVID-19 restrictive measures, works began to appear comparing traditional methods of teaching anatomy with remote methods [7-9]. So far, very few such studies exist; hence this issue requires further research. Moreover, different perspectives from several countries and continents could be beneficial.

Aim of the present study was to determine the impact of COVID-19 outbreak on anatomy teaching to medical and dental students at the Aristotle University of Thessaloniki and compare the traditional anatomy teaching method with three methods of remote teaching: online anatomy lectures, pre-recorded anatomy lectures, and self-teaching by studying the anatomy lectures' presentation.

\section{Materials and Methods}

\section{Study design and population}

The current study took place during the summer semester of the academic year 2019 to 2020. The participants were first-year (2nd semester) and second-year (4th semester) medical and dental students attending the courses of Musculoskeletal System Anatomy and Neuroanatomy of the Department of Anatomy and Surgical Anatomy, School of Medicine, Faculty of Health Sciences, of the Aristotle University of Thessaloniki, Greece.

The pre-COVID era weekly schedule of the musculoskeletal system anatomy course in first-year students consisted of two-hour laboratory lectures and one-hour practical laboratory, including anatomical structures' demonstration on dried cadaveric bones from our laboratory collection, for 15 weeks (a total of 45 hours per semester). As for the secondyear students, the neuroanatomy course in the pre-COVID era included one-hour theoretical lectures and two-hour laboratory education for 15 weeks (a total of 45 hours per semester). The two-hour laboratory education consisted of one hour theoretical and another one practical part with demon- stration of anatomical structures (such as brain sections, nuclei and cranial nerves origin, etc.) on $\mathrm{SOMSO}^{\circledR}$ hand-made plastic anatomical models of organs of the human central nervous system (such as cerebral hemispheres, brain stem, etc.). A group of students of the same course underwent a two-hour education every Monday to be able to perform the demonstration to their classmates. The second-year (4th semester) students had already been taught neuroanatomy during cadavers' dissections in the anatomy courses of the 3rd semester.

In February 2020, before the emergency measures introduction, traditional face-to-face teaching was performed according to the previously described format for 2 weeks. After the enforcement of emergency measures and the transition of the Aristotle University of Thessaloniki to remote work, musculoskeletal anatomy and neuroanatomy courses also changed. The musculoskeletal system anatomy course was then weekly and consisted of one-hour online or pre-recorded theoretical lectures and one-hour online or pre-recorded laboratory lectures. The online lectures were presented live as a teleconference using the "share-screen" function on the Skype for Business ${ }^{\circledR}$ (Microsoft, Redmond, WA, USA) program to present the PowerPoint slides to the students for 8 weeks. The official platform of the Aristotle University of Thessaloniki for e-learning (elearning.auth.gr ${ }^{\circledR}$; Meducator, Thessaloniki, Greece) was used to provide students the link to join the teleconference for the online lectures. Another 5 weeks, pre-recorded lectures were performed. In this format, the professor recorded their voice in the PowerPoint file presenting the lesson without an audience and then shared with the students the created video file on the e-learning platform, including the slides and the Professor's voice. The absence of demonstrations on dried cadaveric bones was substituted with photographs of every aspect of the dried bones from our laboratory collection indicating the anatomical structures. As for the Neuroanatomy course, it was weekly, and consisted of one-hour online or pre-recorded theoretical lectures and one-hour online or pre-recorded laboratory lectures. The absence of anatomical structures demonstrations on plastic models was substituted with photographs of all aspects of those models and photographs of cadaveric brain specimens indicating each anatomical structure. At the beginning of each online lesson, a PowerPoint file of the current lesson (without voice guidance) was sent to the Skype for Business general chat. Thus, students who followed the online lesson were able any time to perform a self-study by 
using the lecture's material.

A total of 420 students were asked to fill in a questionnaire, giving their opinion about the format of anatomy teaching during the COVID-19 outbreak and compare it with the traditional face to face teaching.

The questionnaire consisted of two parts: one general and one specific. The general part included questions, such as demographics data, university, and academic year as well as each participant's level of internet use for educational and entertainment purposes. The specific part enclosed questions regarding the comparison and evaluation of the four different teaching methods: "traditional anatomy lecture", "online anatomy lecture", "pre-recorded anatomy lecture", and "selfteaching by studying the anatomy lectures' presentation". The "anatomy lectures" material included information from classic anatomical atlases, photos of anatomical models and cadaveric images with the goal to become the teaching material as interactive as possible. A translated sample of all questions is presented in Table 1.
The students' June exam period grades of the pre-pandemic year (2018-2019 academic year) were compared to those of the pandemic year (2019-2020 academic year), in order to determine how the transition of the traditional teaching into remote teaching methods affected the students' learning outcomes.

\section{Data collection}

Data were obtained by an online questionnaire available in Google Forms ${ }^{\circledR}$ (Alphabet Inc., Mountain View, CA, USA; https://google.com/forms/about). Google Forms is an online tool that allows collecting information from users through a personalized survey or quiz. The information is then collected and automatically linked to a spreadsheet. At first, the questionnaire was sent to two of the co-authors (MT, TT) to obtain feedback regarding the clarity of the questions. Then, it was sent to all participants via chat during an online lecture on the Skype for Business ${ }^{\circledR}$ platform. Afterwards, the answers were collected automatically upon the questionnaire

Table 1. Translated sample of questions asked in the questionnaire

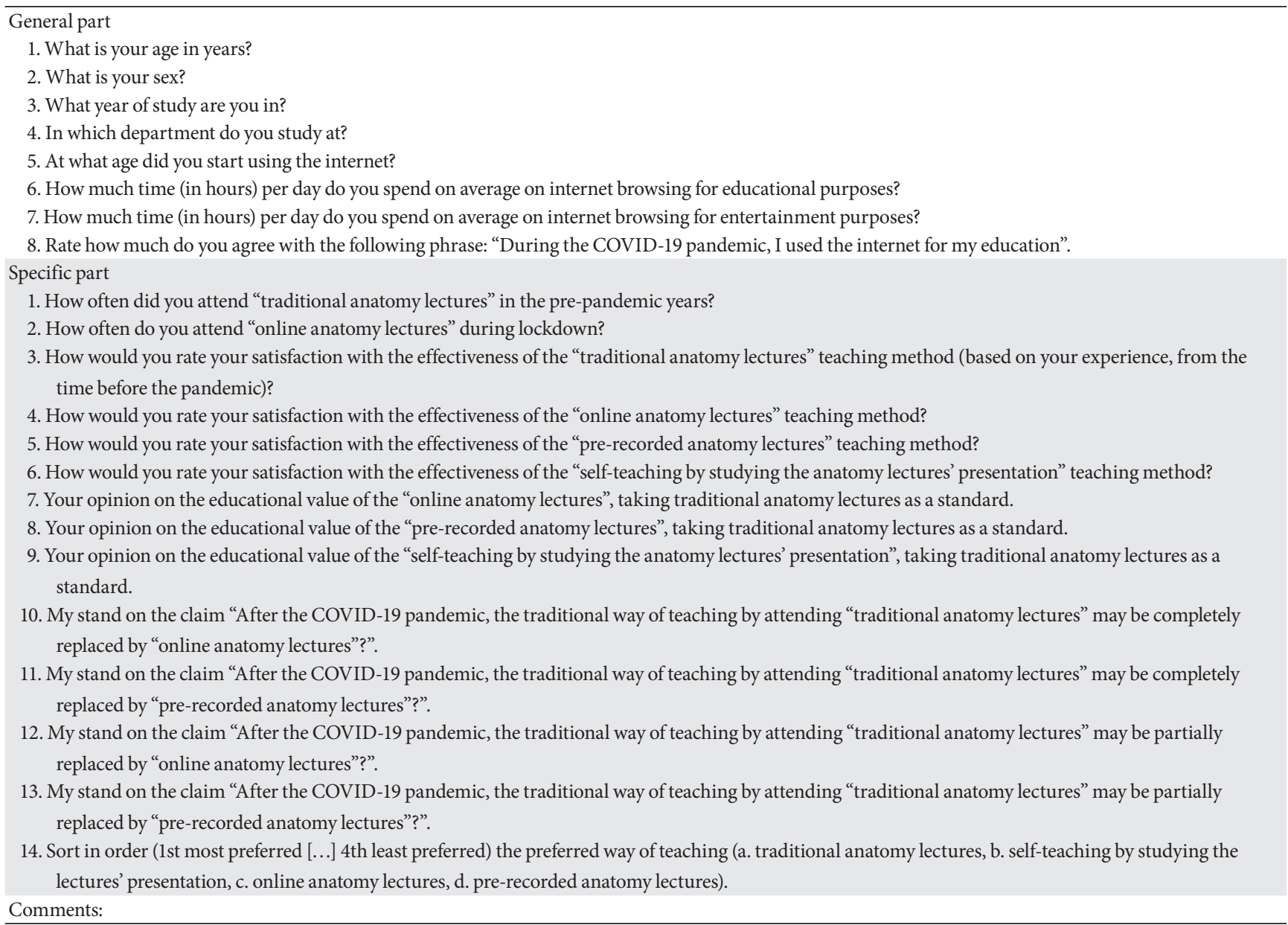


completion by each participant. The students' feedback was obtained during the last two lessons, after 13 weeks of remote anatomy education. Responses from all questionnaires were registered in a database using 2020 Microsoft Excel for Macintosh.

\section{Statistical analysis}

Statistical analysis was performed using the IBM SPSS software ver. 26 (IBM Corp., Armonk, NY, USA). The students' demographic characteristics (sex, academic year, age group, and School) were tabulated. The survey data were analyzed using descriptive statistics to determine the frequency distribution (\%) of the responses. The chi-square test was applied to examine the significance in the differences between students' exam grades before and after the pandemic. The significance level was set at $P<0.05$. Normality of the distributions was also controlled.

\section{Ethics statement}

The questionnaire was submitted to the Ethical Committee of the Medical School, where ethical permission was granted (approval number: 4290). The questionnaire completion was voluntary. Participants could refuse to participate with no problems or considerations. In the first page of the online questionnaire (https://forms.gle/tMPfKydYv8CebHuU9), study participants were informed that their answers

Table 2. Baseline characteristics of the students $(n=200)$

\begin{tabular}{lc}
\hline Characteristic & \multicolumn{1}{c}{ Value } \\
\hline Age (yr) & $20.66 \pm 4.25$ \\
Sex & $76(38.0)$ \\
Male & $124(62.0)$ \\
Female & \\
Academic year & $123(61.5)$ \\
1st & $77(38.5)$ \\
2nd & \\
School & $151(75.5)$ \\
Medical & $49(24.5)$ \\
Dental &
\end{tabular}

Values are presented as mean \pm SD or number (\%).

Table 3. How much time do students spend on the internet?

\begin{tabular}{lcc}
\hline \multicolumn{1}{c}{ Item } & $\begin{array}{c}\text { For educational } \\
\text { purposes }\end{array}$ & $\begin{array}{c}\text { For entertainment } \\
\text { purposes }\end{array}$ \\
\hline Less than an hour & $11(5.5)$ & $20(10.0)$ \\
1-2 hours & $63(31.5)$ & $57(28.5)$ \\
2-4 hours & $80(40.0)$ & $79(39.5)$ \\
4-6 hours & $37(18.5)$ & $38(19.0)$ \\
More than 6 hours & $9(4.5)$ & $6(3.0)$ \\
\hline
\end{tabular}

Values are presented as number (\%). were highly confidential and anonymous. Subsequently, they were asked to give their consent for participating before being guided to the questionnaire. Only participants that gave their informed written consent were able to continue.

\section{Results}

A total of 200 students out of the 420 (47.6\%), with a mean age of $20.66 \pm 4.25$ years (range, $18-50$ years) completed the questionnaire. One hundred and twenty-four participants were female $(62.0 \%)$ and 76 were male (38.0\%). The respondents were 1 st year/2nd semester $(61.5 \%, n=123)$ and 2 nd year/4th semester $(38.5 \%, n=77)$ students. They attended either medical $(75.5 \%, n=151)$ or dental school $(24.5 \%, n=49)$ (Table 2). In terms of internet use, participants stated that the average age of starting computer use was $12.31 \pm 3.74$ years (range, 4-44 years). Also, after the COVID-19 outbreak, $94.0 \%$ ( $n=188$ ) of participants declared that they began to use the internet more often than before. Students spent similar time on the Internet for educational and entertainment purposes (Table 3). Before the pandemic, only $44.5 \%(n=89)$ of participants stated that they constantly attended "anatomy lectures", whereas during the lockdown, the number of students attending each lecture increased by $15.0 \%$ and reached $59.5 \%(n=119)$ (Table 4$)$. When assessing student satisfaction in terms of the effectiveness of each teaching method, $73.5 \%(n=147)$ of students were satisfied with the effectiveness of traditional anatomy lectures, 56.0\% $(n=112)$ with the online anatomy lectures, $52.5 \%(n=105)$ with the prerecorded anatomy lectures, and only $21.5 \%(n=43)$ with the self-teaching by studying the anatomy lectures' presentation (Table 5). Examining the value of each remote modality of anatomy teaching, taking traditional anatomy lectures as a standard, the following results were acquired: $69.0 \%(n=138)$, $63.0 \%(n=126)$ and $31.0 \%(n=62)$ of students considered online anatomy lectures, pre-recorded anatomy lectures and self-teaching by studying the anatomy lectures' presentation,

Table 4. Student participation in lectures before COVID-19 pandemic and during lockdown

\begin{tabular}{ccc}
\hline Item & $\begin{array}{c}\text { Before the } \\
\text { COVID-19 pandemic }\end{array}$ & $\begin{array}{c}\text { During } \\
\text { lockdown }\end{array}$ \\
\hline $100 \%$ lectures & $89(44.5)$ & $119(59.5)$ \\
$\geq 75 \%$ lectures & $43(21.5)$ & $48(24.0)$ \\
$=50 \%$ lectures & $30(15.0)$ & $23(11.5)$ \\
$\leq 25 \%$ lectures & $37(18.5)$ & $10(5.0)$ \\
$0 \%$ lectures & $1(0.5)$ & $0(0)$ \\
\hline
\end{tabular}

Values are presented as number (\%). 
Table 5. Student satisfaction with the effectiveness of each method of teaching anatomy

\begin{tabular}{lcccc}
\hline \multicolumn{1}{c}{ Item } & Traditional anatomy lecture & Online anatomy lecture & Pre-recorded anatomy lecture $\begin{array}{c}\text { Self-teaching by studying the } \\
\text { anatomy lectures' presentation }\end{array}$ \\
\hline Satisfied & $147(73.5)$ & $112(56.0)$ & $105(52.5)$ & $43(21.5)$ \\
Dissatisfied & $53(26.5)$ & $88(44.0)$ & $94(47.0)$ & $151(75.5)$ \\
Unknown & $0(0)$ & $0(0)$ & $1(0.5)$ & $6(3.0)$ \\
\hline
\end{tabular}

Values are presented as number (\%).

Table 6. The value of each remote way of teaching anatomy, taking traditional anatomy lectures as a standard

\begin{tabular}{cccc}
\hline Item & Online anatomy lecture & Pre-recorded anatomy lecture & $\begin{array}{c}\text { Self-teaching by studying the } \\
\text { anatomy lectures' presentation }\end{array}$ \\
\hline Valuable & $138(69.0)$ & $126(63.0)$ & $62(31.0)$ \\
Invaluable & $18(9.0)$ & $29(14.5)$ & $81(40.5)$ \\
Unknown & $44(22.0)$ & $45(22.5)$ & $57(28.5)$ \\
\hline
\end{tabular}

Values are presented as number (\%).

Table 7. Opinion of students on the prospect of complete or partial replacement of the traditional method of teaching anatomy with remote methods

\begin{tabular}{lcc}
\hline \multicolumn{1}{c}{ Item } & $\begin{array}{c}\text { Online } \\
\text { anatomy lecture }\end{array}$ & $\begin{array}{c}\text { Pre-recorded } \\
\text { anatomy lecture }\end{array}$ \\
\hline Completely & & \\
Yes & $29(14.5)$ & $28(14.0)$ \\
No & $133(66.5)$ & $137(68.5)$ \\
Unknown & $38(19.0)$ & $35(17.5)$ \\
Partially & & \\
Yes & $69(34.5)$ & $59(29.5)$ \\
No & $72(36.0)$ & $96(48.0)$ \\
Unknown & $59(29.5)$ & $45(22.5)$ \\
\hline
\end{tabular}

Values are presented as number (\%).

respectively, to be equivalent to traditional anatomy lectures as a teaching tool (Table 6). When analyzing students' view on whether any remote educational method can partially or completely replace traditional anatomy teaching the majority of students replied "no" for all three remote methods. However, 69 students (34.5\%) and another 59 students (29.5\%) declared that online anatomy lectures and pre-recorded anatomy lectures, respectively, could partially replace the traditional teaching (Table 7). As for the preferable teaching method, $49.0 \%$ ( $\mathrm{n}=98)$ of students indicated traditional anatomy lectures as the most preferred teaching modality. Self-teaching by studying the anatomy lectures' presentation was indicated as the least preferable teaching modality $(\mathrm{n}=25$, 12.5\%) (Table 8). We also compared the students' exam grades in musculoskeletal system anatomy and neuroanatomy between the pre-pandemic (2018-2019) and the pandemic (2019-2020) academic year. In musculoskeletal anatomy, the mean exam score for students in the pre-pandemic year was $6.88 \pm 2.12$ (range, $0-10$ ), while in the pandemic year was $6.59 \pm 1.67$ (range, $0-9$ ). In neuroanatomy, the mean exam score was $6.10 \pm 2.23$ (range, $0-10$ ) in the pre-pandemic academic year and 5.70 \pm 1.61 (range, $0-10$ ) in the pandemic academic year. Both differences in exam grades were statistically significant, (chi-square test, for both $P<0.001$ ) (Table 9).

\section{Discussion}

The COVID-19 pandemic has led to the transition from traditional to online education in medical schools. The use of modern technologies in the current situation helps educational institutions and students to continue the learning process and acquire new skills. However, holding onto the students' attention during online lectures is a rather serious problem [10]. Furthermore, it is important to evaluate the effectiveness and impact of the transition to online education.

The most important findings of the present study are that the traditional anatomy teaching method through face-to-face lectures remains the most preferred and effective teaching modality according to students. Second in terms of effectiveness and students' preference occur both the online anatomy lectures and the pre-recorded anatomy lectures, with similar results. The self-teaching by studying the anatomy lectures' presentation is considered the least effective and preferred method. An interesting finding is that the remote teaching methods' development has increased the active participation of students in the anatomy lessons. The majority of students do not believe that remote teaching can completely replace the traditional anatomy teaching method. However, one third of the students consider that the online lectures or the pre-recorded lectures could be implemented in the anatomy curricula. Furthermore, the transition from the traditional teaching method into remote methods seems 
Table 8. Students' preferences for the anatomy teaching methods

\begin{tabular}{ccccc}
\hline Item & Traditional anatomy lecture & Online anatomy lecture & Pre-recorded anatomy lecture $\begin{array}{c}\text { Self-teaching by studying the } \\
\text { anatomy lectures' presentation }\end{array}$ \\
\hline 1st place & $98(49.0)$ & $46(23.0)$ & $44(22.0)$ & $25(12.5)$ \\
\hline
\end{tabular}

Values are presented as number (\%).

Table 9. Comparison of students' exam grades following remote anatomy teaching during the pandemic year (2019-2020 academic year) with the grades following the pre-pandemic traditional anatomy teaching (2018-2019 academic year)

\begin{tabular}{ccccc}
\hline Anatomy course & Academic year & No. of students & Exam grade & $P$-value \\
\hline Musculoskeletal system anatomy & $2018-2019$ & 252 & $6.88 \pm 2.12(0-10)$ & $<0.001^{*}$ \\
(2nd semester of the 1st year students) & $2019-2020$ & 272 & $6.59 \pm 1.67(0-9)$ & $<.10 \pm 2.23(0-10)$ \\
Neuroanatomy & $2018-2019$ & 211 & $5.70 \pm 1.61(0-10)$ & $<0.001^{*}$ \\
(4th semester of the 2nd year students) & $2019-2020$ & 295 & & \\
\hline
\end{tabular}

Values are presented as mean $\pm \mathrm{SD}$ (range). ${ }^{*}$ Statistically significant value (chi-squared test).

to affect the students' performance at exams.

Both the online anatomy lectures and pre-recorded lectures left $56.0 \%$ and $52.5 \%$ of students satisfied. These findings, are similar to the $53.5 \%$ reported in Sharma et al. [11] study and close to the $63.4 \%$ in Cuschieri and Agius [12] cohort. However, in the relevant literature there are studies mentioning more than $87 \%$ satisfaction $[7,13]$, contrariwise to others reporting lower than $14 \%$ satisfaction $[8,14]$ with the online educational methods in health sciences (medicine, dentistry, pharmacy etc.). In an older study, Pourghaznein et al. [15] reported that student satisfaction with the online learning was significantly lower compared to traditional lectures.

Half of the students declared traditional anatomy lectures as the most preferred teaching modality. This preference rate is much higher than the corresponding rate found for any online educational method. Similar results can be found in other studies, as Zhang et al. [16] mentioned the preference of the $54.17 \%$ of the students for the traditional anatomy lectures compared to online lectures. Singh et al. [17] found that $50.9 \%$ of students rated traditional anatomy lectures as the preferred teaching method and $22.1 \%$ preferred online anatomy lectures being in accordance with the $23 \%$ found in the current study.

The greater satisfaction to the traditional anatomy education could be attributed to the fact that students are more familiar with traditional lectures and may feel more isolated in a virtual learning environment without eye contact with the teacher. The speed and adequacy of the internet connection, the availability of technical assistance, and the quality of the online program of the lectures may also negatively affect the student's satisfaction with e-learning $[18,19]$. Other studies have shown that students' satisfaction with the remote education methods increased when they were equipped with the latest technology. Lack of training and technical knowledge prevented users from taking full advantage of remote teaching education systems, thereby reducing student satisfaction [20].

In line with the findings in terms of student satisfaction and preference, only a minority (14.5\%) of students suggested, that online educational modalities can completely replace traditional methods. However, $34.5 \%$ of the students would like some of the lectures to become remotely. In studies coming from Nepalese, Pakistani and Kuwait students, it was highlighted that $89.8 \%, 77 \%$ and $51.2 \%$ of these students respectively, prefer to continue the online lectures $[11,21$, 22]. This inconsistency may reflect different perspectives between Nations and disparities in the traditional and /or the online learning modalities. Moreover, students' skills play an important role in their online learning satisfaction. Students who are proficient in appropriate educational technologies can continue their studies with remote teaching methods without problems [23].

The students noted that they attended online lectures more frequently than traditional ones. This is supported by Liaw et al. [24] as well, who reported that remote educational modalities have higher attendance compared to the traditional lectures. This observation is another reason to implement some online courses in the traditional anatomy education curricula.

Online medical teaching is a challenge since students during medical education need to learn and work directly with patients. Anatomy education based on the laboratory specimens' demonstration is characterized by the necessity for the 
student to understand the 3D topography and anatomical structures relations [25]. The e-learning modality results in a loss of "hands-on" experience affecting workload, traditional roles, pedagogy, and personal educational philosophy of anatomy teachers (the so-called anatomists) [26]. However, anatomy educators should continue to participate in remote learning even after the pandemic restrictions will be lifted. Advancement of the quality of remote teaching modalities during this period could be utilized in the future by them as an additional tool in their arsenal.

The current study should be interpreted in the context of the following limitations. The quality of each participant's local internet connection was out of the department's control and thus, many problems in attending efficiently the online anatomy lectures could have been reflected to less satisfaction with the online modalities. The subjects of the study were from only one university, which limits the external validity of the current findings. However, this is another reason for the necessity of the present study and more similar studies reflecting perspectives on this topic from different regions around the world.

In conclusion, the COVID-19 pandemic has affected all aspects of the human life, and medical students were not an exception. Comparing several remote education methods to the traditional face to face anatomy teaching, the present study revealed that the traditional anatomy teaching method remains the most preferred and effective teaching modality for students. The students ranked online anatomy lectures and pre-recorded anatomy lectures in the second place in terms of effectiveness and preference. Self-teaching by studying the anatomy lectures' presentation was considered the least preferred by the students. However, the development of remote learning methods has increased the active participation of students in anatomy lessons. The current research also clarifies that remote learning cannot replace the traditional anatomy teaching method. Online lectures could be incorporated into anatomy curricula as an additional educational tool.

\section{ORCID}

Trifon Totlis: https://orcid.org/0000-0001-5729-7755

Maksim Tishukov:

https://orcid.org/0000-0002-7220-960X

Maria Piagkou: https://orcid.org/0000-0002-4831-8005

Michael Kostares: https://orcid.org/0000-0001-9183-4622
Konstantinos Natsis:

https://orcid.org/0000-0002-3077-1784

\section{Author Contributions}

Conceptualization: TT, KN. Data acquisition: MT. Data analysis or interpretation: TT, MT, MP. Drafting of the manuscript: TT, MT, MP, MK. Critical revision of the manuscript: TT, KN. Approval of the final version of the manuscript: all authors.

\section{Conflicts of Interest}

No potential conflict of interest relevant to this article was reported.

\section{Acknowledgements}

The authors express their gratitude to Stavros Papadopoulos, MS, for his contribution to the completion of this study. Moreover, the authors would like to express their great appreciation to the students that accepted the invitation to participate in the study survey.

\section{References}

1. Lewis KO, Cidon MJ, Seto TL, Chen H, Mahan JD. Leveraging e-learning in medical education. Curr Probl Pediatr Adolesc Health Care 2014;44:150-63.

2. Harden RM. Trends and the future of postgraduate medical education. Emerg Med J 2006;23:798-802.

3. Green RA, Whitburn LY, Zacharias A, Byrne G, Hughes DL. The relationship between student engagement with online content and achievement in a blended learning anatomy course. Anat Sci Educ 2018;11:471-7.

4. Trelease RB. From chalkboard, slides, and paper to e-learning: how computing technologies have transformed anatomical sciences education. Anat Sci Educ 2016;9:583-602.

5. Estai M, Bunt S. Best teaching practices in anatomy education: a critical review. Ann Anat 2016;208:151-7.

6. Lochner L, Wieser H, Waldboth S, Mischo-Kelling M. Combining traditional anatomy lectures with e-learning activities: how do students perceive their learning experience? Int J Med Educ 2016;7:69-74.

7. Srinivasan DK. Medical students' perceptions and an anatomy teacher's personal experience using an e-learning platform for tutorials during the COVID-19 crisis. Anat Sci Educ 2020;13:318-

8. Singal A, Bansal A, Chaudhary P. Cadaverless anatomy: darkness 
in the times of pandemic COVID-19. Morphologie 2020;104:14750.

9. Korkmaz FT, Gürses IA. Initial effects of COVID-19 pandemic on graduate anatomy education in Turkey. Anatomy 2020;14:12333.

10. Bawa P. Retention in online courses: exploring issues and solutions- a literature review. SAGE Open 2016. doi: 10.1177/ 2158244015621777.

11. Sharma K, Deo G, Timalsina S, Joshi A, Shrestha N, Neupane HC. Online learning in the face of COVID-19 pandemic: assessment of students' satisfaction at Chitwan Medical College of Nepal. Kathmandu Univ Med J (KUMJ) 2020;18:40-7.

12. Cuschieri S, Agius JC. Spotlight on the shift to remote anatomical teaching during COVID-19 pandemic: perspectives and experiences from the University of Malta. Anat Sci Educ 2020;13:671-9.

13. Seada AI, Mostafa MF. Students' satisfaction and barriers of elearning course among nursing students, Mansoura University. World J Nurs Sci 2017;3:170-8.

14. George PP, Papachristou N, Belisario JM, Wang W, Wark PA, Cotic Z, Rasmussen K, Sluiter R, Riboli-Sasco E, Tudor Car L, Musulanov EM, Molina JA, Heng BH, Zhang Y, Wheeler EL, Al Shorbaji N, Majeed A, Car J. Online eLearning for undergraduates in health professions: a systematic review of the impact on knowledge, skills, attitudes and satisfaction. J Glob Health 2014;4:010406.

15. Pourghaznein T, Sabeghi H, Shariatinejad K. Effects of e-learning, lectures, and role playing on nursing students' knowledge acquisition, retention and satisfaction. Med J Islam Repub Iran 2015;29:162.

16. Zhang Q, He YJ, Zhu YH, Dai MC, Pan MM, Wu JQ, Zhang X, Gu YE, Wang FF, Xu XR, Qu F. The evaluation of online course of Traditional Chinese Medicine for MBBS international students during the COVID-19 epidemic period. Integr Med Res 2020;9:100449.
17. Singh K, Srivastav S, Bhardwaj A, Dixit A, Misra S. Medical education during the COVID-19 pandemic: a single institution experience. Indian Pediatr 2020;57:678-9.

18. Mirza AA, Al-Abdulkareem M. Models of e-learning adopted in the Middle East. Appl Comput Inf 2011;9:83-93.

19. Tarus JK, Gichoya D, Muumbo A. Challenges of implementing e-learning in Kenya: a case of Kenyan public universities. Int Rev Res Open Distrib Learn 2015;16:120-41.

20. Bahramnezhad F, Asgari P, Ghiyasvandian S, Shiri M, Bahramnezhad F. The learners' satisfaction of e-learning: a review article. Am J Educ Res 2016;4:347-52.

21. Abbasi S, Ayoob T, Malik A, Memon SI. Perceptions of students regarding E-learning during COVID-19 at a private medical college. Pak J Med Sci 2020;36(COVID19-S4):S57-61.

22. Al-Fahad FN. The learners' satisfaction toward online elearning implemented in the College of Applied Studies and Community Service, King Saud University, Saudi Arabia: can e-learning replace the conventional system of education? Turkish Online J Distance Educ 2010;11:61-72.

23. Johnson AM, Jacovina ME, Russell DG, Soto CM. Challenges and solutions when using technologies in the classroom. In: Crossley SA, McNamara DS, editors. Adaptive Educational Technologies for Literacy Instruction. New York: Taylor and Francis; 2017. p.13-29.

24. Liaw SS, Huang HM, Chen GD. Surveying instructor and learner attitudes toward e-learning. Comput Educ 2007;49:1066-80.

25. Cho MJ, Hwang YI. Students' perception of anatomy education at a Korean medical college with respect to time and contents. Anat Cell Biol 2013;46:157-62.

26. Pather N, Blyth P, Chapman JA, Dayal MR, Flack NAMS, Fogg QA, Green RA, Hulme AK, Johnson IP, Meyer AJ, Morley JW, Shortland PJ, Štrkalj G, Štrkalj M, Valter K, Webb AL, Woodley SJ, Lazarus MD. Forced disruption of anatomy education in Australia and New Zealand: an acute response to the COVID-19 pandemic. Anat Sci Educ 2020;13:284-300. 